\title{
ERRATUM
}

\section{P. Knauth}

\section{Defect and transport properties of nanocrystalline ceramics and thin films}

Published online: 8 March 2002

(C) Springer-Verlag 2002

\section{J Solid State Electrochem (2002) 6:165-171}

Due to an unfortunate error in the printed version (pdf) Fig. 4 was repeated as Fig. 3. The correct Fig. 3 is printed below.

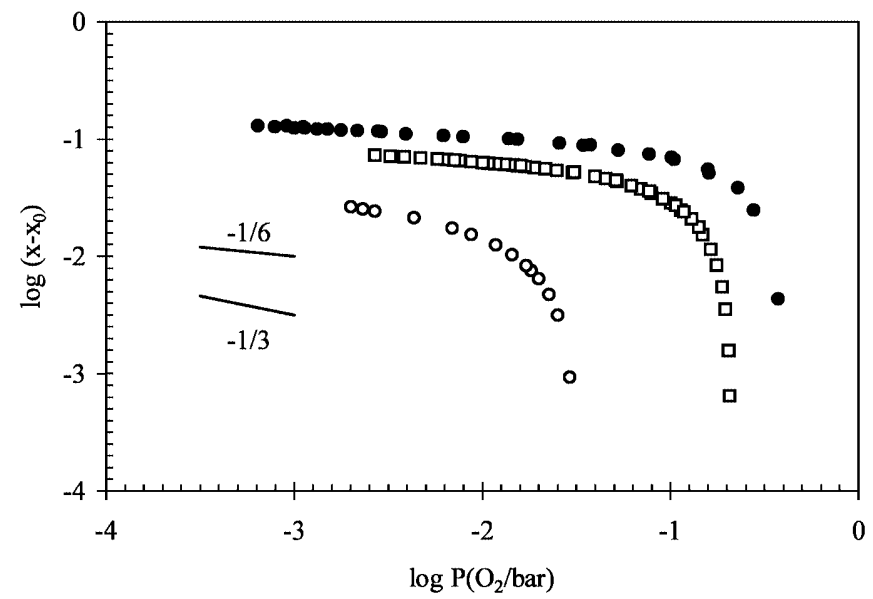

Fig. 3 Relative oxygen deficiency $\left(x-x_{0}\right)$ of $\operatorname{Pr}_{0.7} \mathrm{Ce}_{0.3} \mathrm{O}_{2-x}$ at 470 (open circles), 560 (squares), and $640{ }^{\circ} \mathrm{C}$ (filled circles) as a function of the oxygen partial pressure. From [37]

The online version of the original article can be found at http:// dx.doi.org/10.1007/s10008-001-0258-z

P. Knauth

MADIREL, Université de Provence-CNRS (UMR 6121),

Centre St. Charles, Case 26, 13331 Marseille Cedex 3, France

E-mail: knauth@up.univ-mrs.fr

Tel.: + 33-491-106-296

Fax: + 33-491-106-237 